\title{
Coronary slow flow in patients with impaired glucose tolerance and insulin resistance
}

\author{
Yasser Gaber Metwally ${ }^{1 *}$, Heba Kamal Sedrak ${ }^{2}$ and Inas Fahiem Shaltout ${ }^{2}$
}

\begin{abstract}
Background: The relationship between coronary slow flow (CSF) and insulin resistance (IR) is still a subject of debate with conflicting data. So the aim was to assess the relationship between IR as measured by IR index (HOMA-IR) and coronary slow flow as measured by the TIMI frame count in patients which (impaired glucose tolerance (IGT) and IR.
\end{abstract}

Results: Out of 87 patients enrolled, 64 (73.6\%) patients were assigned to the IGT group while 23 (26.4\%) patients were assigned to the NGT group. There were significantly higher BMI $(30.15 \pm 2.29$ vs $23.90 \pm 2.5, P<0.001)$, waist circumference (105.05 \pm 9.0 .06 vs $92.92 \pm 16.5, P<0.001)$, and frequency of hypertension (60.9\% vs $34.8, P=0.03)$. Also, there were significantly higher 2 -h post-prandial (hPP) glucose (161 \pm 30 vs $110 \pm 20, P<0.05)$, fasting serum insulin level ( $9.56 \pm 2.5$ vs $7.03 \pm 2.1, P<0.001), \mathrm{HDL}(40 \pm 6.5$ vs $49 \pm 5.6, P<0.001)$, HOMA-IR index $(2.84 \pm 0.03$ vs $1.6 \pm 0.05, P<0.05$ ), and mean TIMI frame count (33 \pm 5 vs $26 \pm 4, P<0.001$ ) among the IGT group, while HDL was significantly lower in the IGT group ( $40 \pm 6.5$ vs $49 \pm 5.6, P<0.001)$. There was a highly significant positive correlation between TIMI frame count and HOMA-IR $(r=0.43, P<0.001)$; predictors that add significance to the model were age $>50$ years, hypertension, high waist circumference, $\mathrm{HDL}<35$, and HOMA-IR. For HOMA-IR (OR $95 \% \mathrm{Cl}=1.9(1.05-3.49), P=0.02$ demonstrating that HOMA-IR is a powerful independent predictor of high TIMI frame count (Table 4).

Conclusion: IR is an independent risk factor for slow coronary flow in patients with IGT. Those with evident coronary slow flow, IGT should be managed aggressively even before any evidence of frank diabetes. Also, IR workup should be recommended among the other standard workup for those patients; if documented, targeting IR in such patients should be a priority (whenever possible) while selecting medications for comorbid cardiac disease, as well as using interventions targeted against IR should be considered among the other standard management for slow flow.

Keywords: Coronary slow flow, Impaired glucose tolerance, Insulin resistance

\section{Background}

Pre-diabetes is a condition that has been described by the American diabetic association (ADA) and includes those with impaired fasting glucose level [1]. Fifty percent of patients with prediabetes are estimated to develop overt diabetes mellitus within a 10-year course [2]. Mortality

\footnotetext{
* Correspondence: yassercardio@gmail.com

'Department of Cardiology, Faculty of Medicine, Zagazig University, Zagazig, Egypt

Full list of author information is available at the end of the article
}

and future MACE are increased in patients with prediabetes $[3,4]$. Both diabetics and pre-diabetics are more frequently screened for coronary artery disease and even with angiographically normal coronary arteries; still have a considerably increased risk for future MACE [4]. Insulin resistance (IR) is well known for promoting coronary artery disease (CAD) even with the severity of CAD due to IR [5-7]. But we still evaluate the CSF-IR relationship with conflicting data; we hypothesize that IR plays a role in coronary slow flow in patients with glucose intolerance

\section{Springer Open}

(c) The Author(s). 2020 Open Access This article is licensed under a Creative Commons Attribution 4.0 International License, which permits use, sharing, adaptation, distribution and reproduction in any medium or format, as long as you give appropriate credit to the original author(s) and the source, provide a link to the Creative Commons licence, and indicate if changes were made. The images or other third party material in this article are included in the article's Creative Commons licence, unless indicated otherwise in a credit line to the material. If material is not included in the article's Creative Commons licence and your intended use is not permitted by statutory regulation or exceeds the permitted use, you will need to obtain permission directly from the copyright holder. To view a copy of this licence, visit http://creativecommons.org/licenses/by/4.0/. 
and IR. The aim of this study therefore was to investigate the relationship between IR (measured by the HOMA-IR) and coronary slow flow (measured by TIMI frame counts) in glucose intolerance and IR patients.

\section{Methods}

This study was conducted from January 2018 to May 2020.

The study included and enrolled 87 consecutive patients in this study who were diagnosed as CSF as evidenced by invasive coronary angiography after excluding coronary plaques or obstructive coronary artery disease or overt diabetes mellitus. Peripheral vascular disease, uncontrolled systemic hypertension, cerebrovascular accident, left ventricular ejection fraction $<50 \%$, valvular heart disease, thyroid hormonal dysfunction, malignancy, pregnancy, septicemia, thrombocytopenia, chronic inflammatory disease, and hepatic or renal insufficiency were other exclusion criteria. The patients then were assigned into two groups according to the presence or absence of IGT into (IGT group, $n=64$ ) or NGT group (NGT group, $n=$ 23). The research was compiled by the CONSORT 2010 [8] and the Helsinki Declaration. All participants were fully informed in written. Coronary angiography was conducted using the Judkins method to identify patients of angina symptoms which could not be sufficiently described by noninvasive imaging. Two experienced cardiologists, not informed of the scopes of the study and of each other, visually evaluated both angiograms.

\section{TIMI frame count evaluation of coronary slow flow}

For coronary flow assessment, the time elapsed between the appearance of the contrasting agent and the distal end of either the left anterior descending (LAD) artery, circumflex artery, or the right coronary artery was regarded as the thrombolysis in MI frame count (TIMI). The final count became deducted from the initial count, and the specified artery was determined for each TIMI frame count. Nevertheless, when the LAD artery was the case, it was divided by 1.7 . The cutoff values were defined by Gibson et al. according to the TIMI frame count method [9]: $36.2 \pm 2.6$ LAD frames, $22.2 \pm 4.1$ circumflex frames, and $20.4 \pm 3.0$ right coronary artery frames. The revised LAD coronary artery cutoff value was $21.3 \pm 1.5$ frame. Any frame count above these thresholds is considered to be slow coronary.

\section{Blood samples and analysis}

After $12 \mathrm{~h}$ of fasting, blood samples were collected from patients. The Rouche Medical Integrated Systems Analyzer includes plasma glucose levels and performed all routine blood tests. A 75-g glucose load was given orally in patients under WHO (WHO) guidelines, and plasma glucose levels were determined by an enzymatic glucose oxidase process
(Roch Company, Ontario, Canada). Chemilumino metric immunoassay measured insulin levels (DPC-Immunite 2000, No. 152).

IR assessment using the Homeostasis Assessment Model (HOMA-IR) arises from the mathematical modeling of fasting glucose and insulin concentrations [10]. The HOMA-IR model is an easy, practical, and cheap method of IR assessment compared to the Euglycemic clamp. HOMA-IR formula: fasting insulin level $(\mu \mathrm{U} / \mathrm{ml}) \times$ fast glucose $(\mathrm{mg} / \mathrm{dl}) / 405$ [11]. Subjects with values exceeding 75 percentiles (i.e., 2.0) is known to have resistance to insulin (HOMA-IR index) [12]. Lipid profile also measured [13], $\mathrm{HbA}_{1} \mathrm{C}$, hs-CRP, and other routine clinical as well as laboratory testing was done.

\section{Definitions}

Normal fasting glucose (NFG), impaired fasting glucose (IFG), and DM were defined as fasting glucose level < $100 \mathrm{mg} / \mathrm{dL}, 100-125 \mathrm{mg} / \mathrm{dL}$, and > $126 \mathrm{mg} / \mathrm{dL}$, respectively. Impaired glucose tolerance is defined as a 2-h postprandial glucose level between 140 and $199 \mathrm{mg} / \mathrm{dL}$. Body mass index (BMI) was calculated by dividing weight $(\mathrm{kg})$ by the square of height $\left(\mathrm{m}^{2}\right)$. The presence of the metabolic syndrome was diagnosed according to the modified national cholesterol education programadult treatment panel III (NCEP-ATP III) criteria [14]. The primary endpoint was assessing the relationship between IR as measured by IR index (HOMA-IR) coronary slow flow as measured by the TIMI frame count.

\section{Statistical analysis}

The continuous variables were expressed in mean \pm SD while discrete variables were expressed in percentage. The differences in continuous variables were checked for statistical significance by student $t$ test as appropriate, and the differences in the discrete variables were checked for statistical significance by $X^{2}$ test. Multiple regression analysis had been done between the TIMI frame count indicative of slow coronary flow versus variables predicting its occurrence. Also, correlation had been done using a post hoc test.

$P$ value $<0.05$ was considered significant. The statistical analysis was performed using SPSS.11 for Windows (SPSS Inc., Chicago, IL, USA).

\section{Results}

Out of 87 patients enrolled, 64 (73.6\%) patients were assigned to the IGT group while $23(26.4 \%)$ patients were assigned to the NGT group. The demographic and clinical variables of our study population are shown in Table 1 . No statistically significant differences in the age, gender, frequency of smokers, or prior MI were found between the two groups. On the other hand, there were significantly higher BMI $(30.15 \pm 2.29$ vs $23.90 \pm 2.5, P<$ 
Table 1 Demographic and clinical variables

\begin{tabular}{llll}
\hline & $\begin{array}{l}\text { IGT group } \\
\text { (No = 64) }\end{array}$ & $\begin{array}{l}\text { NGT group } \\
\text { (No = 23) }\end{array}$ & P value \\
\hline Age (years) & $51.7 \pm 9$ & $51.2 \pm 10$ & 0.82 \\
Male gender & $42(65.6 \%)$ & $15(65.2 \%)$ & 0.97 \\
Waist circum (cm) & $105.05 \pm 9.06$ & $92.92 \pm 16.5$ & $<0.001^{*}$ \\
BMI $\left(\mathrm{kg} / \mathrm{m}^{2}\right)$ & $30.15 \pm 2.29$ & $23.90 \pm 2.50$ & $<0.001^{*}$ \\
Hypertension & $39(60.9 \%)$ & $8(34.8 \%)$ & $0.03^{*}$ \\
Dyslipidemia & $22(34.4 \%)$ & $5(21.7 \%)$ & $>0.05$ \\
Smoking & $45(70.3 \%)$ & $15(65.2 \%)$ & 0.65 \\
Prior Ml & $8(12.5 \%)$ & $3(13 \%)$ & $>0.05$ \\
\hline
\end{tabular}

$B M I$ body mass index, $M I$ myocardial infarction

${ }^{*} P<0.05$, significant

$0.001)$, waist circumference $(105.05 \pm 9.06 .5$ vs $92.92 \pm$ $16.5, P<0.001)$, and frequency of hypertension $(60.9 \%$ vs $34.8, P<0.03)$.

Biochemical, echocardiographic, and angiographic variables of our study population are shown in Table 2. No statistically significant differences in the TG, LDL, uric acid, fasting blood glucose level, or EF\% were found between the two groups. On the other hand, there were significantly higher 2 -hPP glucose $(161 \pm 30$ vs $110 \pm 20$, $P<0.05)$, fasting serum insulin level $(9.56 \pm 2.5$ vs 7.03 $\pm 2.1, P<0.001)$, HDL $(40 \pm 6.5$ vs $49 \pm 5.6, P<0.001)$, and HOMA-IR index $(2.84 \pm 0.03$ vs $1.6 \pm 0.05, P<$ $0.05)$ shown in Fig. 1; mean TIMI frame count $(33 \pm 5$ vs $19 \pm 2, P<0.001)$ among the IGT group. While HDL was significantly lower in the IGT group ( $40 \pm 6.5$ vs 49 $\pm 5.6, P<0.001)$.

The correlation was done using Pearson's correlation coefficients. There was a highly significant positive correlation between TIMI frame count and HOMA-IR $(r=0.43, P<0.001)$ (Table 3$)$.

Table 2 Echocardiography laboratory angiographic variables

\begin{tabular}{llll}
\hline & $\begin{array}{l}\text { IGT group } \\
\text { (No = 64) }\end{array}$ & $\begin{array}{l}\text { NGT group } \\
\text { (No = 23) }\end{array}$ & P value \\
\hline F. glucose $(\mathrm{mg} / \mathrm{dl} \%)$ & $82 \pm 10$ & $80 \pm 7$ & $>0.05$ \\
2 h B sugar $(\mathrm{mg} / \mathrm{dl} \%)$ & $161 \pm 30$ & $110 \pm 20$ & $<0.05^{*}$ \\
F. serum insulin $(\mu \mathrm{U} / \mathrm{ml})$ & $9.65 \pm 2.5$ & $7.03 \pm 2.1$ & $<0.001^{* *}$ \\
HOMA-IR & $2.8 \pm 1.0$ & $1.68 \pm 0.6$ & $<0.05^{*}$ \\
HDL $(\mathrm{mg} / \mathrm{dl})$ & $40 \pm 6.5$ & $49 \pm 5.6$ & $<0.001^{* *}$ \\
TG $(\mathrm{mg} / \mathrm{dl})$ & $170 \pm 15$ & $166.1 \pm 10.5$ & 0.22 \\
LDL $(\mathrm{mg} / \mathrm{dl})$ & $90 \pm 20$ & $86 \pm 15$ & 0.38 \\
Uric acid $(\mathrm{mg} / \mathrm{dl})$ & $6.1 \pm 3.5$ & $5.0 \pm 2.5$ & 0.17 \\
EF\% & $59 \pm 4$ & $60 \pm 5$ & 0.33 \\
T1Ml frame count & $33 \pm 5$ & $19 \pm 2$ & $<0.001^{* *}$ \\
\hline
\end{tabular}

HOMA-IR homeostasis model, HDL high-density lipoprotein, $L D L$ low-density lipoprotein, EF\% ejection fraction, TIMI Thrombolysis in Myocardial Infarction $* P<0.05$, significant

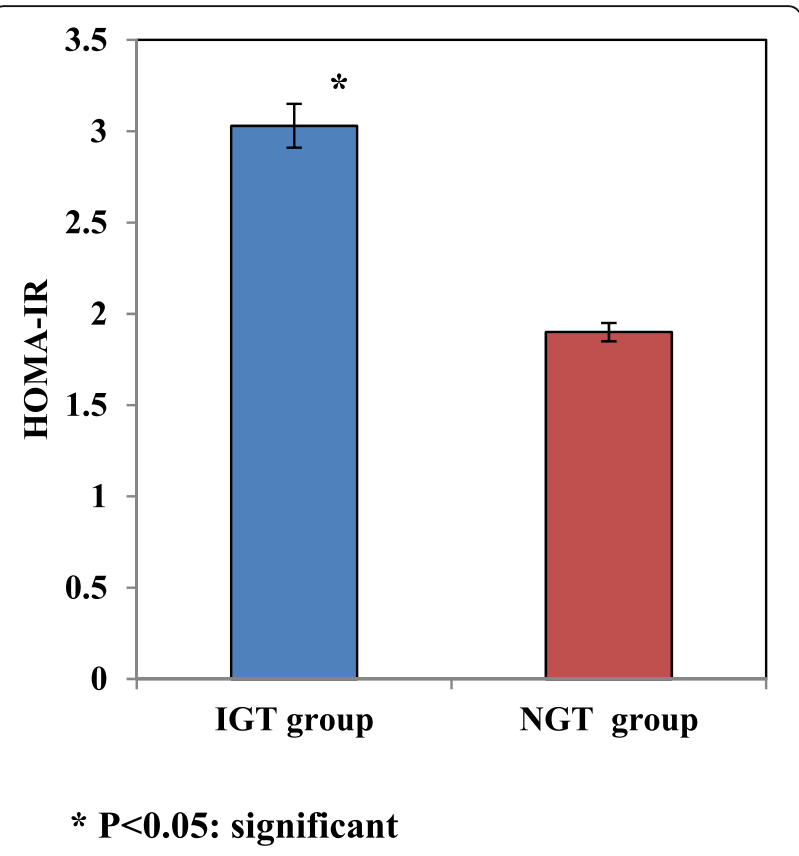

Fig. 1 HOMA-IR among the study groups

Multiple regression analysis was done and revealed that predictors that add significance to the model were age > 50 years, hypertension, high waist circumference, HDL < 35, and HOMA-IR. For HOMA-IR (OR 95\% CI $=1.9(1.05-3.49)), P=0.02$ demonstrating that HOMAIR is a powerful independent predictor of high TIMI frame count (Table 4).

\section{Discussion}

Coronary slow flow is a well-recognized clinical entity, characterized by delayed opacification of coronary arteries despite normal coronary angiography [15]. TIMI frame count provides an assessment of the basal microvascular

Table 3 Correlation between T1M1 frame count and other variables

\begin{tabular}{lll}
\hline & $\boldsymbol{r}$ & $\boldsymbol{P}$ \\
\hline Age & 0.38 & $<0.001^{*}$ \\
BMl $\left(\mathrm{kg} / \mathrm{m}^{2}\right)$ & 0.49 & $<0.001^{*}$ \\
Waist circumference $(\mathrm{cm})$ & 0.45 & $<0.001^{*}$ \\
HOMA-IR & 0.43 & $<0.001^{*}$ \\
2hpp suger (mg/dl) & 0.39 & $<0.001^{*}$ \\
F. Serum insulin (IU/ml) & 0.41 & $<0.001^{*}$ \\
HDL(mg/dl) & -0.56 & $<0.001^{*}$ \\
Systolic Bp & 0.36 & $<0.001^{*}$ \\
Diastolic Bp & 0.37 & $<0.001^{*}$ \\
\hline
\end{tabular}

$B M I$ body mass index, HOMA-IR homeostasis model, HDL high-density lipoprotein, $B P$ blood pressure, 2 hpp 2-hour post-prandial ${ }^{*} P<0.05$, significant 
Table 4 Multiple regression analysis predictors of high T1M1 frame count

\begin{tabular}{lll}
\hline & OR $(\mathbf{9 5} \% \mathrm{Cl})$ & \\
\hline Age $>50$ ys & $1.83(1.01-3.35)$ & $0.03^{*}$ \\
Waist circumference & $2.79(1.51-5.6)$ & $0.001^{*}$ \\
HOMA-IR & $1.91(1.05-3.49)$ & $0.02^{*}$ \\
HTN & $2.25(1.23-4.13)$ & $0.004^{*}$ \\
$\mathrm{HDL}<35(\mathrm{mg} / \mathrm{dl})$ & $1.91(1.05-3.49)$ & $0.02^{*}$ \\
\hline
\end{tabular}

HOMA-IR homeostasis model, HDL high-density lipoprotein, HTN hypertension ${ }^{*} P<0.05$, significant

tone [16], and a higher TIMI frame count may be a reflection of microvascular resistance [17]. The interrelationship between IR, vasomotor endothelial function, and glucose intolerance was discussed above $[1,2,4,15,18-21]$. We relied more, for our patient group classification, on IGT rather than IFG because the role of IGT is relatively more important in the IR pathophysiology [22].

The results of our study demonstrated that a higher mean TIMI frame count is indicative of coronary slow flow among patients with IGT and IR. Several pathophysiological mechanisms have been implicated including microvascular and endothelial dysfunction [18-21].

CSF could reflect lower coronary flow reserve [23], an endothelial function that can be measured also with more sensitive tools such as acetylcholine test or noninvasive ultrasound-based flow-mediated dilation. IR is related to the vaso-motor dysfunction of the endothelial cells. Previous clinical trials had investigated the relation between IR versus coronary slow flow.

El-Sherbiny et al. [24] found that IR in patients without overt diabetes mellitus is associated with the slow coronary flow. Again, Turhan et al. [25] found that in patients with IR on top of metabolic syndrome, TIMI frame counts were higher. Those findings were similar to the present study, but different from that of Yazici and colleagues' [26], who studied the association between slow coronary flow versus serum glucose and insulin. They found no link between the adjusted TIMI frame count and the levels of serum glucose and insulin. Nevertheless, only the basal serum insulin without the homeostatic pattern was measured, not the IR investigated.

\section{Study limitations}

Initially, our sample size was fairly limited and we wanted a bigger, randomized, standardized, multi-center analysis. Furthermore, since our research demographic was a selectively targeted group, most of the patients were in cardiology clinics with confirmed CAD in coronary angiography. Thirdly, a large percentage of our patients were hypertensive, taken B-blockers and diuretics that understood to have an effect on glucose homeostasis.

\section{Conclusion}

IR is an independent risk factor for slow coronary flow in patients with IGT and metabolic syndrome. Those with evident coronary slow flow, IGT should be managed aggressively even before any evidence of frank diabetes. Also, IR workup should be recommended among the other standard workup for those patients; if documented, targeting IR in such patients should be a priority (whenever possible) while selecting medications for co-morbid cardiac disease, as well as using interventions targeted against IR should be considered among the other standard management for slow flow.

\section{Abbreviations}

BMI: Body mass index; CONSORT: Consolidated Standards Of Reporting Trials; CSF: Coronary slow flow; HOMA-IR: Homeostatic Model Assessment for Insulin Resistance; IGT: Impaired glucose tolerance; IR: Insulin resistance; NCEP-ATP: National Cholesterol Education Program - adult treatment panel; NGT: Normal glucose tolerance; MACE: Major cardiovascular event;

TIMI: Thrombolysis in myocardial infarction

\section{Acknowledgements}

Not applicable

\section{Authors' contributions}

All authors contributed significantly to the research and reviewed and approved the final manuscript file. No authors have been removed or newly added. All authors certified the author list and contribution description. No authors are listed who do not deserve authorship credit, and the authors' contributions provided are expressed accurately. Y.M. had participated in the concept, design, definition of intellectual content, literature search, clinical studies, experimental studies, data acquisition, data analysis, statistical analysis, manuscript preparation, manuscript editing, and manuscript review and is the guarantor of the study. H.S. contributed to the literature review, analysis of data, methodology implementation, processing statistics, and review of the manuscript draft. I.S. contributed to the methodology implantation, literature review, data analysis and interpretation, and review of the manuscript draft. All authors had reviewed and approved the final manuscript file before giving signatures.

Funding

All authors declare that no financial or special source of funds.

Availability of data and materials

All data and material of the research are available from the corresponding author on reasonable request.

Ethics approval and consent to participate

This study was approved by the ethics committee of the Faculty of Medicine, Zagazig University, with the approval number IRB\#2916/7-1-2018. (The full name of the ethics committee is the Institutional Review Board of Faculty of Medicine, Zagazig University). The patient provided written consent.

Consent for publication

Not applicable.

Competing interests

All authors declare that they have no competing interests.

\section{Author details}

${ }^{1}$ Department of Cardiology, Faculty of Medicine, Zagazig University, Zagazig, Egypt. ${ }^{2}$ Department of Internal Medicine, Faculty of Medicine, Cairo University, Cairo, Egypt. 
Received: 31 July 2020 Accepted: 11 September 2020

Published online: 24 November 2020

\section{References}

1. American Diabetic Association (2008) Diagnosis and classification of diabetes mellitus. Diabetes Care (Suppl. I):S55-S60

2. Stratton IM, Adler AL, Neil HA et al (2000) Association of glycemia with macrovascualr and microvascualr complications of type 2 diabetes (UKPDS 35): prospective observational study. BMJ 321:405-412

3. Anand SS, Dagenais GR, Mohan V, Diaz R, Probstfield J, Freeman R, Jung $H$ (2012) Glucose levels are associated with cardiovascular disease and death in an international cohort of normal glycaemic and dysglycaemic men and women: the EpiDREAM cohort study. Eur J Prev Cardiol 19(4):755-764

4. Barr EL, Zimmet PZ, Welborn T (2007) A et al. Risk of cardiovascular and allcause mortality in individuals with diabetes mellitus, impaired fasting glucose, and impaired glucose tolerance: the Australian Diabetes, Obesity, and Lifestyle Study (AusDiab). Circulation 116(2):151-157

5. Yan Q, Gu WQ, Hong J, Zhang YF, Su YX, Gui MH, Ning G (2009) Coronary angiographic studies of impaired glucose regulation and coronary artery disease in Chinese nondiabetic subjects. Endocrine 36(3):457-463

6. Adeva-Andany MM, Ameneiros-Rodríguez E, Fernández-Fernández C, Domínguez-Montero A, Funcasta-Calderón R (2019) Insulin resistance is associated with subclinical vascular disease in humans. World J Diabetes 10(2):63

7. Pyörälä M, Miettinen $\mathrm{H}$, Laakso $M$ et al (2000) Plasma insulin and all-cause, cardiovascular, and noncardiovascular mortality: the 22-year follow-up results of the Helsinki Policemen Study. Diabetes Care 23(8):1097-1102

8. Schulz KF, Altman DG, Moher D (2010) CONSORT 2010 statement: updated guidelines for reporting parallel group randomized trials. Ann Internal Med 152(11):726-732

9. Gibson CM, Cannon CP, Daley WL et al (1996) TIMI frame count: a quantitative method of assessing coronary artery flow. Circulation 93(5): 879-888

10. Honing ML, Morrison PJ, Banga JD et al (1998) Nitric oxide availability in diabetes mellitus. Diabetes Metab Rev 14(3):241-249

11. Wallace TM, Levy JC, Matthews DR (2004) Use and abuse of HOMA modeling. Diabetes Care 27(6):1487-1495

12. Balkau B, Charles MA, Drivsholm T et al (2002) Frequency of the WHO metabolic syndrome in European cohorts, and an alternative definition of an insulin resistance syndrome. Diabetes Metab 28(5):364

13. Mehrotra R, Pandya S, Chaudhary A (2010) Lipids. Helath Dis 8:29

14. Grundy SM, Cleeman Jl, Daniels SR et al (2005) Diagnosis and management of the metabolic syndrome: an American Heart Association/National Heart, Lung, and Blood Institute Scientific Statement. Circulation 112:2735-2752

15. Mullasari A, Victor SM (2013) Coronary slow flow phenomenon. E-J Eur Soc Cardiol Council Cardiol Pract 11:25-04

16. Tanedo JS, Kelly RF, Marquez M et al (2001) Assessing coronary blood flow dynamics with the TIMI frame count method: comparison with simultaneous intracoronary Doppler and ultrasound. Catheter Cardiovasc Interv 53(4):459-463

17. Goodwill AG, Dick GM, Kiel AM, Tune JD (2011) Regulation of coronary blood flow. Comprehensive Physiol 7(2):321-382

18. Sezgin AT, Sgrc A, Barutcu I, Topal E et al (2003) Vascular endothelial function in patients with slow coronary flow. Coron Artery Dis 14(2): 155-161

19. Taqueti VR, Di Carli MF (2018) Coronary microvascular disease pathogenic mechanisms and therapeutic options: JACC state-of-the-art review. J Am Coll Cardiol 72(21):2625-2641

20. Mangieri E, Macchiarelli G, Ciavolella M et al (1996) Slow coronary flow: clinical and histopathological features in patients with otherwise normal epicardial coronary arteries. Catheter Cardiovasc Diagn 37(4):375-381

21. Erbay AR, Turhan $H$, Senen $K$ et al (2004) Documentation of slow coronary flow by the thrombolysis in myocardial infarction frame count in habitual smokers with angiographically normal coronary arteries. Heart Vessel 19(6): 271-274

22. Schianca GPC, Rossi A, Sainaghi PP, Maduli E et al (2003) The significance of impaired fasting glucose versus impaired glucose tolerance: importance of insulin secretion and resistance. Diabetes Care 26(5):1333-1337

23. Akasaka T, Yoshida K, Hozumi T et al (1997) Retinopathy identifies marked restriction of coronary flow reserve in patients with diabetes mellitus. J Am Coll Cardiol 30(4):935-941
24. Elsherbiny IA, Shoukry A, El Tahlawi MA (2012) Mean platelet volume and its relation to insulin resistance in non-diabetic patients with slow coronary flow. J Cardiol 59(2):176-181

25. Turhan H, Erbay AR, Yasar et al (2004) Impaired coronary blood flow in patients with metabolic syndrome: documented by Thrombolysis in Myocardial Infarction (TIMI) frame count method. Am Heart J 148(5): 789-794

26. Yazici M, Demircan S, Aksakal E et al (2003) Plasma insulin, glucose and lipid levels and their relations with correlated TIMI frame count in patients with slow coronary flow. Turkish Anadolu Kardiyol Derg 3:227-229

\section{Publisher's Note}

Springer Nature remains neutral with regard to jurisdictional claims in published maps and institutional affiliations.

\section{Submit your manuscript to a SpringerOpen ${ }^{\circ}$ journal and benefit from:}

- Convenient online submission

- Rigorous peer review

- Open access: articles freely available online

- High visibility within the field

- Retaining the copyright to your article

Submit your next manuscript at $>$ springeropen.com 